\title{
Which competitive advantages can firms really obtain from ISO14001 certification?
}

\author{
Josefina L. Murillo-Luna; Juan C. Ramón-Solans-Prat \\ University of Zaragoza (SPAIN) \\ jmurillo@unizar.es; steiner@unizar.es
}

Received September 2008

Accepted November 2008

\begin{abstract}
Ten years after the introduction of ISO14001, in this paper we present empirical evidence about the competitive advantages that managers associate to this environmental practice, from a sample of industrial firms located in Spain. The results indicate that the potential competitive advantages are: improvement of the internal efficiency, differentiation advantages, attention to the stakeholders' requirements, enhancement of the competitive position in the sector and financial savings. Nevertheless managers' expectations of improving internal efficiency might be the real reason that encourages firms to make the voluntary decision of investing in ISO14001 certification.
\end{abstract}

Keywords: ISO14001, competitive advantages, industrial firms

\section{Introduction}

The increasing awareness about the environmental impact of industrial activity has endorsed the development of different standards that guide and try to integrate the environmental management systems in firms. The most widespread one is ISO14001 which was officially published in September 1996 (Alberti, Caini, Calabrese \& Rossi, 2000).

ISO14001 standard provides an orientation for the establishment of environmental management systems that can help firms demonstrate publicly their commitment with the protection of the natural environment. It is based on three principles: 
pollution prevention, continuous improvement and voluntary participation (Bansal \& Hunter, 2003). Sarkis (1998) lists five elements or steps that describe the successful implementation process of environmental management systems (EMSs) based on ISO14001 (Figure 1):

- Environmental policy: Firms must capture in a written document their intentions and principles in relation to their environmental behaviour. This statement must show firms' commitment to comply with environmental legislation, to prevent pollution and also to potentially improve their environmental performance. It also must be accessible for the public.

- Planning: Firms have to identify controllable environmental aspects and determine which ones have significant environmental impacts. These are the ones that firms should attend first. Then firms have to determine the legal dimensions of these impacts (which will depend on the sector, the geographical situation...) and, based on this information, they have to establish objectives and targets as well as the EMS to achieve them.

- Implementation and operation: It means the allocation of human, financial and physical resources for these issues. Managers have to assign the environmental responsibilities, provide the suitable training to employees and also establish the internal and external communication channels in order to spread the environmental commitment among all the members in the organization and the stakeholders.

- Checking and corrective action: It includes the measurement of environmental performance, the identification of deviations by comparing targets and results and the application of corrective actions when necessary. In order to be able to carry out these activities, firms must keep environmental records and have periodical auditing of the EMSs.

- Management review: In order to guarantee the effectiveness and continuous improvement of the EMSs, managers have to review and get a feedback of all the policies, objectives and procedures.

The literature suggests that the adoption of environmental protection measures provides firms the opportunity to both take care the natural environment and improve their competitive positions (Hart, 1995; Sharma \& Vredenburg, 1998). 
Nevertheless, Christmann (2000) specifies that different best practices of environmental management affect different types of competitive advantages.

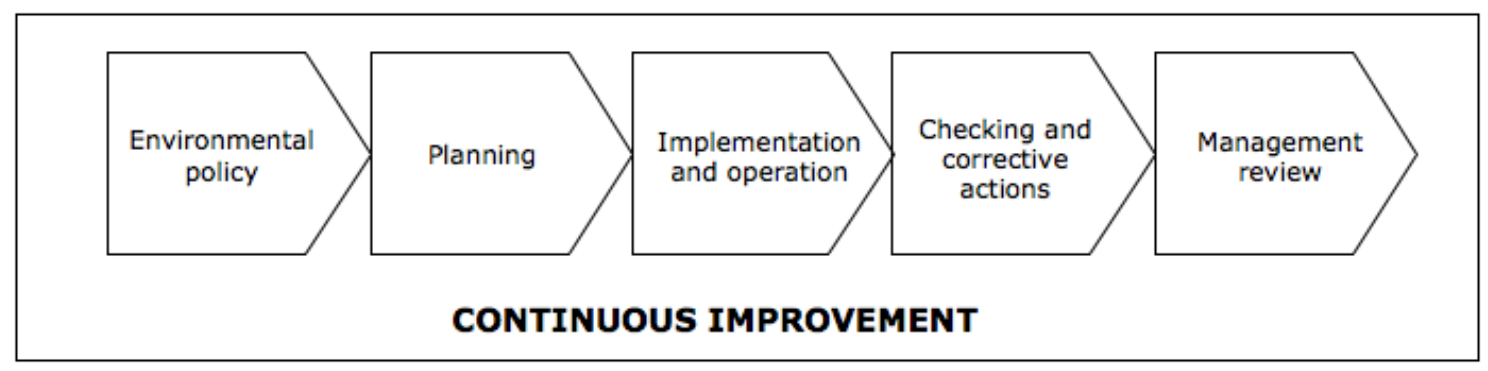

Figure 1. "Implementation process of EMSs based on ISO 14001".

Bansal and Hunter (2003) distinguish two levels when explaining the objectives of ISO14001: on the one hand, at a corporate level to advice and guide firms to reduce their environmental impact through identification, measurement and control activities; on the other hand, at a societal level to provide an internationally legitimised system of standardization that fosters international trade. Nevertheless, few studies focus on the analysis of the competitive advantages that firms can get from ISO14001 certification. The lack of empirical evidence provokes scepticism among managers about the potential results of these types of environmental investments (Simpson, Taylor \& Barker, 2004), so it is necessary to bring additional research that shows the competitive advantages that firms can really get by protecting the natural environment with specific environmental practices (Banerjee, 2001). Then in order to make an empirical contribution to the management field related to natural environment, the main objective of this paper is to identify the competitive advantages that managers really associate to ISO14001 certification.

With this objective in mind, this paper is structured as follows: In the following section we put forward the main theoretical contributions that we gathered from a review of the literature on the topic. Next, we describe the sample, we define the variables, and we emphasize the basic aspects of the analysis methodology. Then we present the results obtained in the empirical analyses. Finally, we summarise the main conclusions of the research. 


\section{The environmental variable as a competitive advantage source}

Most of the competitive advantages that theoretical literature has associated to the environmental protection measures adopted by firms can be described through Porter's (1980) framework, which distinguishes between cost advantages and differentiation advantages.

On the one hand, different authors have found that certain environmental practices can provide cost advantages. For example, the technologies that firms can use to reduce their environmental impact have been generally classified into two groups: pollution control and pollution prevention technologies. The formers try to reduce pollution once it has been originated. They are called "end-of-pipe technologies" and do not require modifications in the existing production processes. The latters are aimed to minimize the pollution created in the production process. They are more expensive, but they can help firms increase the efficiency production (Hart, 1995). Life cycle analysis can also be a source of cost advantages (Tien, Chung \& Tsai, 2005). It implies making a holistic analysis of product's impact on the natural environment along its whole life cycle - exploration of raw materials, design, manufacturing, transportation, sales, use and disposal-. A specific practice which is based on life cycle analysis approach is the design for environment (Hart, 1997). It involves considering the complete product life cycle when designing the environmental aspects of products or processes (Sarkis, 1998), in order to minimise the environmental impact of product use and disposal. It requires the development of products with a maximum useful life and that are easy to disassemble and recycle (Shrivastava, 1995).

How can these environmental practices provide cost advantages? Different authors, such as Zutshi and Sohal (2004), explain that these initiatives can lead to cost reductions because of more efficient use of raw materials/energy, reduction of treatment costs of wastes, improvements of firms' production processes, savings from recycling activities (which not only allow firms being less polluting by preventing discharges but it can even provide the opportunity to create new markets with re-used rejects), reduction of potential risks of environmental liabilities costs, reduction of logistic costs through better housekeeping and safety stock management or organisational improvements and better knowledge of working procedures (for example, through better communication across the 
organization with ISO 14001 certification, as all its members use the same EMS terminology).

On the other hand, we mentioned differentiation advantages. They can result from different measures aimed to product characteristics and product markets. For example, the redesign of packaging and products in order to reduce the volume of natural resources used, the development of new "green" products or the advertising of the environmental attributes of the products. According to Bansal and Roth (2000), there is an emergent and growing consumer segment which appreciates the sustainable practices of firms. Furthermore, Delmas (2001) states that these consumers might be even willing to pay a price premium for "environmentally friendly" products and/or services. Then it is possible to achieve higher revenues by increasing prices and enhancing the market share, thanks to differentiation advantages such as the improvement of the environmental attributes of products and/or services or the satisfaction of clients' environmental requirements.

Cost and differentiation advantages are the most acknowledged competitive advantages associated to the adoption of environmental protection initiatives. Nevertheless, Shrivastava (1995), Bansal \& Roth (2000), Delmas (2001) and Zutshi and Sohal (2004), among others, mention some other advantages which managers might also associate to ISO14001 certification. They are basically related to the attention to the stakeholders' requirements, the achievement of financial savings and the enhancement of the competitive position:

Financial savings and improvement of relationships with regulators: Firms not only avoid liability costs and non-compliance fines, but they can also demonstrate their interest in taking care of the natural environmental.

Improvement of relationships with other stakeholders: For example, firms can obtain better conditions from investment and insurance companies. It also reduces the risk of serious accidents and provides a guarantee to suppliers of the firm's environmental commitment.

Anticipation of future environmental pressures: In the last decades there has been an increasing environmental awareness among society. As a consequence, firms are being forced to satisfy their stakeholders' environmental requirements (Madu, 2004). ISO14001 certification is a voluntary initiative that can allow firms to get 
ahead of more stringent environmental regulations and even might allow them to influence the development of some environmental regulations. Leniency on international trade barriers: ISO14001 certification can help firms be competitive in global markets.

Achievement of first-mover advantages: It can provide firms the opportunity to improve their competitive position in the sector and become environmental leaders or gain first-mover advantages.

According to the arguments presented above, we propose the following hypotheses:

- Hypothesis 1a. Managers' perceptions of the cost advantages that their firms can gain from ISO14001 certification take them to make the decision of obtaining this certification.

- Hypothesis 1b. Managers' perceptions of the differentiation advantages that their firms can gain from ISO14001 certification take them to make the decision of obtaining this certification.

- Hypothesis 1c. Managers' perceptions of the competitive advantages related to the attention to the stakeholders' requirements, the achievement of financial savings and the enhancement of the competitive position that their firms can gain from ISO14001 certification, take them to make the decision of obtaining this certification.

\section{The empirical base}

\subsection{Data collection and sample}

We have focused our study on the population of Spanish industrial firms with at least 20 workers located in Aragón, an industrialised region of medium size situated in the north-eastern part of Spain, and listed on SABI database, which comprises historical economic and financial information from 880.000 Spanish enterprises and 87.000 Portuguese enterprises since 1990. In July 2006 they were 1,175 firms. We contacted 408 firms that we selected by simple random sampling and 98 of them agreed to participate in this study. We could not reach the suitable 
person for the study in 93 firms and 217 firms explicitly rejected to participate in the study. It represents a response rate of $35 \%$.

We collected data regarding these firms through primary sources, more specifically, the application of a structured questionnaire. During the month of July 2006 we had a telephone interview with the person responsible for environmental matters at the firm or, if there was no such person, the general manager. Before asking the questionnaire, we explained the purpose of the study to the respondents and we gave them some instructions on how to answer the questionnaire in the interview, with the aim of reducing the number of incomplete or wrong surveys to a minimum.

In the questionnaire we included questions that were designed to obtain information about the competitive advantages that managers associate to ISO14001 certification, as well as about the status of ISO14001 certification at their firms. These questions were based on theoretical literature on the topic.

We also used secondary sources to check that the information provided by respondents about the ISO14001 certification status was correct. More specifically, we used the records that IHOBE, S.A., a stated-owned company from Basque Country (Spain), keeps of all the Spanish firms that have ISO14001 certification. IHOBE provides the only complete and monthly updated listing of Spanish firms with ISO14001 and EMAS certification, with the collaboration of the environmental certification organizations (http://www.ihobe.net).

The number of valid surveys was 94 , after deleting 4 cases because of incomplete or incorrect information. We present in table 1 the information about the sample firms. There we can observe that most of them are SMEs.

The sectorial and size distribution of the sample firms did not substantially differ from the distribution presented by the population of firms targeted in our research. Indeed, the differences between the sample segments and the population segments did not exceed the sampling error (9.48\%). Then we can conclude that the sample is representative of the population. 


\begin{tabular}{|llc|}
\hline \multicolumn{1}{|c|}{ Variable } & \multicolumn{1}{c|}{ Description } & $\%$ \\
\hline SIZE: & From 20 to 31 workers & $22 \%$ \\
Number of employees & From 31 to 50 workers & $29 \%$ \\
(N=94) & From 51 to 100 workers & $23 \%$ \\
& More than 100 workers & $26 \%$ \\
\hline ISO 14001 & Yes & $25 \%$ \\
CERTIFICATION & $\sim$ Before 2000 & $5 \%$ \\
(N=94) & $\sim$ In 2001-2003 & $10 \%$ \\
& $\sim$ In 2004-2006 & $8 \%$ \\
& $\sim$ No answer & $2 \%$ \\
& No & $75 \%$ \\
\hline
\end{tabular}

${ }^{a}$ Percentages calculated based on the number of responses obtained for each variable.

Table 1. "Description of the sample firms".

\subsection{Definition of the variables and methodology}

\section{Competitive advantages}

In order to reach the objective of this paper, we defined the variables for assessing managers' perceptions of the different competitive advantages that firms can obtain from ISO14001 certification. According to literature on the topic, we proposed 26 variables for which we defined eleven categories (0-10), where value 1 meant "ISO 14001 certification absolutely does not provide this competitive advantage" and value 10 meant "ISO14001 definitely provides this competitive advantage".

\section{ISO14001 Certification}

In order to analyse the relationship between ISO14001 certification and the achievement of competitive advantages, we defined a variable to describe the ISO14001 certification status at firms. This variable had two categories, depending on firms having ISO14001 certification or not. For firms with ISO14001 certification, we also asked for the year when they got the certification.

\section{Methodology}

First, we focused on obtaining the underlying structure in the group of competitive advantages related to ISO14001 certification. To do that, we carried out a Principal Component Analysis. This analysis technique allows defining a smaller group of variables, Principal Components, which are capable of synthesising the 
relationships between the variables observed. The number of components to be retained is defined based on the communalities and the percentages of explained variance of the components. After extracting the components, and in order to profile the variable-principal components correspondence, we applied different rotation methods (orthogonal and non-orthogonal) and we assessed their relative Cronbach Alpha score.

Second, in order to analyse the relationship between ISO14001 certification and competitive advantages, first, we created 5 new variables which represent the Principal Components. We calculated the values of these variables based on the arithmetic mean of the individual values of the variables associated with each component. Then we applied an Analysis of Variance (ANOVA), which contrasts the null hypothesis of equal means between two groups of firms (the one of firms with ISO14001 certification and the other one, which does not have ISO14001 certification) in the new variables.

\section{Results}

The mean values presented in Table 2 indicate that managers do not assess in the same way all the competitive advantages associated to ISO14001 certification. The ones that they appreciate the most are the differentiation advantages (improvement of corporate image, satisfaction of client's environmental requirements) and the advantages related to efficiency improvements (improvement of production processes, training for employees). On the other extreme, advantages related to the improvement of relationships with other stakeholders, such as improved access to insurance, better access to financial support or the obtaining of governmental subsidies have an assessment which does not reach 5 points.

The results of the Principal Component Analysis that we carried out on the 26 variables representative of the competitive advantages indicate that they can be summarized in a structure of 5 Principal Components (see table 2): PC1 Improvement of internal efficiency -, PC2 - Differentiation advantages-, PC3 Attention to the stakeholders' requirements -, PC4 - Enhancement of the competitive position in the sector - and PC5 - Financial savings-. Table 2 shows evidence of the adaptation of this five-component structure: the accumulated explained variance reaches $73 \%$, the weights that relate variables to components 
exceed 0.5 and, furthermore, the Cronbach Alpha coefficients exceed 0.70 in all the components.

\begin{tabular}{|c|c|c|c|c|c|c|}
\hline Competitive advantages & $\bar{X}$ a & PC1 & PC2 & PC3 & PC4 & PC5 \\
\hline$v_{1}$. More efficient use of resources & 7.15 & 0.69 & & & & \\
\hline$v_{2}$. Reduction of waste management costs & 7.27 & 0.52 & & & & \\
\hline$v_{3}$. Training for the employees & 7.46 & 0.73 & & & & \\
\hline $\mathrm{v}_{4}$. Increasing of employees' motivation & 6.72 & 0.82 & & & & \\
\hline$v_{5}$. Higher productivity & 6.37 & 0.82 & & & & \\
\hline $\mathrm{v}_{6}$. Better economic performance & 6.02 & 0.53 & & & & \\
\hline $\mathrm{V}_{7}$. Savings from recycling activities & 6.33 & 0.52 & & & & \\
\hline$v_{8}$. Improvement of production processes & 7.62 & 0.81 & & & & \\
\hline$v_{9}$. Synergies with other management systems & 6.25 & 0.58 & & & & \\
\hline $\mathrm{V}_{10}$. Improvement of corporate image & 7.92 & & 0.63 & & & \\
\hline$v_{11}$. Increasing the market share & 5.84 & & 0.59 & & & \\
\hline $\mathrm{v}_{12}$. Satisfaction of clients' environmental requirements & 7.92 & & 0.51 & & & \\
\hline $\mathrm{v}_{13}$. Adaptation to clients' expectations & 7.23 & & 0.88 & & & \\
\hline$v_{14}$. Development of new and green products & 5.84 & & 0.78 & & & \\
\hline \multicolumn{2}{|c|}{$\mathrm{v}_{15}$. Simplification of permissions and governmental licenses5.97 } & & & 0.54 & & \\
\hline$v_{16}$. Better access to international markets & 6.44 & & & 0.63 & & \\
\hline$v_{17}$. New market opportunities & 6.52 & & & 0.58 & & \\
\hline $\mathrm{v}_{18}$. Adaptation to market requirements & 7.72 & & & 0.66 & & \\
\hline$v_{19}$. Environmental leadership in the sector & 6.08 & & & & 0.73 & \\
\hline$v_{20}$. First mover advantages & 5.78 & & & & 0.73 & \\
\hline$v_{21}$. Imitation of competitors' environmental practices & 6.12 & & & & 0.84 & \\
\hline$v_{22}$. Reduction of potential environmental liability risks & $\begin{array}{c}5.1 \\
7\end{array}$ & & & & & 0.69 \\
\hline$V_{23}$. Improved access to insurance & $\begin{array}{c}3.2 \\
8\end{array}$ & & & & & 0.81 \\
\hline$v_{24}$. Better access to financial support & $\begin{array}{c}3.0 \\
8\end{array}$ & & & & & 0.81 \\
\hline$v_{25}$. Access to governmental subsidies & $\begin{array}{c}4.8 \\
6\end{array}$ & & & & & 0.81 \\
\hline$V_{26}$ I Improved relationships with regulators & $\begin{array}{c}6.1 \\
8\end{array}$ & & & & & 0.64 \\
\hline$\%$ explained variance & & $42.66 \%$ & $11.20 \%$ & $9.58 \%$ & $5.07 \%$ & $4.97 \%$ \\
\hline$\%$ accumulated explained variance & & $42.66 \%$ & $53.86 \%$ & $63.44 \%$ & $\begin{array}{c}68.52 \\
\%\end{array}$ & $\begin{array}{c}73.48 \\
\%\end{array}$ \\
\hline Cronbach Alpha Coefficient & & 0.88 & 0.75 & 0.77 & 0.73 & 0.87 \\
\hline
\end{tabular}

${ }^{a}$ Percentages calculated based on the number of responses obtained for each variable.

Table 2. "Competitive advantages-Principal Component Analysis". 
As regards ISO14001 certification, we can observe in table 3 that only $25.5 \%$ of the sample firms have it. Nevertheless, firms are concerned about these issues because we asked to those firms that did not have ISO14001 certification about their willing to get this certification in the future and the results showed that only $31 \%$ of those firms did not plan to obtain this certification in the short or medium term. More than $40 \%$ of those firms expressed their willing to get this certification in the next 6 months and almost 30\% in the next 24 months. Data also showed the increasing salience of environmental issues in firms' decision making process, because more than $60 \%$ of the sample firms had a person in charge of the environmental management.

After obtaining the 5 Principal Components, we prepared 5 variables that were representative of the competitive advantages related to ISO14001 certification, whose values were calculated by means of the arithmetic mean of the variables that formed each Principal Component. In the first column of data in table 3 we include the average values of these 5 variables. We can observe that the highest assessments correspond to the competitive advantages associated to improvement of the internal efficiency and the differentiation advantages. On the contrary, the assessment for the financial saving that ISO14001 certification can provide does not even reach 5 points.

\begin{tabular}{l}
\cline { 3 - 4 } \\
\cline { 3 - 5 }
\end{tabular}

Table 3. "ISO14001 certification and competitive advantage: Variance Analysis". 
In the following columns in table 3 , the average values are listed by groups. We distinguished two groups, the one that includes firms with ISO14001 certification and another one with the rest of firms. Based on these average values, we performed an Analysis of Variance (ANOVA) which contrasts the null hypothesis of equal means between groups of firms in the 5 types of competitive advantages. The results allow rejecting the null hypothesis only in the first variable: Improvement of the internal efficiency. Then the only significant difference between firms with ISO14001 certification and firms without ISO14001 certification is that the first ones show a higher assessment for the competitive advantages related to the improvement of the internal efficiency. The assessment for the rest of the competitive advantages is not significantly different. It means that it is the perception about the competitive advantages that affect firms' internal efficiency the one that might be determinant in the decision of firms of undertaking the challenge of getting ISO14001 certification. These results only support our first Hypothesis. Therefore managers' expectations of improving internal efficiency might be the real reason that encourages firms to make the voluntary decision of investing in ISO14001 certification.

Our results are coherent with Chavan's (2005) argument that an EMS can be a powerful tool not only for improving firm's environmental performance, but also for enhancing their business efficiency. Stead and Stead's (1995) results also indicate that cost reduction is the main economic reason that justifies the implementation of environmental protection measures.

\section{Conclusions}

The relationship between the adoption of environmental protection measures and the achievement of competitive advantages is a current issue (Aragón-Correa \& Sharma, 2003). ISO14001 certification is becoming a critical factor that might determine firms' competitiveness (Angell \& Klassen, 1999). Based on the information obtained from a sample of industrial firms, in this paper we present empirical evidence about the competitive advantages that managers associate to this specific environmental practice.

The results of the study indicate that these potential competitive advantages can be summed up in five groups: improvement of the internal efficiency, differentiation advantages, attention to the stakeholders' requirements, 
enhancement of the competitive position in the sector and financial savings. The ones that they appreciate the most are the ones related to the improvement of the internal efficiency and the differentiation advantages. On the contrary, managers do not consider ISO14001 certification as an important source of financial savings.

As regards the relationships between ISO14001 certification and competitive advantages, although all the firms show high assessments for all potential competitive advantages (except for the financial savings), there is a significant difference between firms with ISO14001 certification and firms without ISO14001 certification. It is their assessment of the competitive advantage related to the improvement of the internal efficiency, which is significantly higher for firms with ISO14001 certification. Therefore managers' expectations of improving internal efficiency might be the real reason that encourages firms to make the voluntary decision of investing in ISO14001 certification.

\section{Acknowledgements}

We thank the anonymous reviewers and professor P. Rivera-Torres for their helpful suggestions and comments. This paper is part of the results obtained in the framework of research project SEJ2005-07341, financed by MEC-FEDER, the CREVALOR Excellence Research Group, acknowledged by the Diputación General de Aragón (Spain).

\section{References}

Alberti, M., Caini, M., Calabrese, A., \& Rossi, D. (2000). Evaluation of the costs and benefits of an Environmental Management system. International Journal of Production Research, 38(17) 4455-4466.

Angell, L. C., \& Klassen, R. D. (1999). Integrating environmental issues into the mainstream: An agenda for research in operations management. Journal of Operations and Production Management, 11(3) 63-76.

Aragón-Correa, A., \& Sharma, S. (2003). A contingent resource-based view of proactive corporate environmental strategy. Academy of Management Review, 28(1) 71-88. 
Banerjee, S. B. (2001). Managerial perceptions of corporate environmentalism: interpretations from industry and strategic implications for organizations. Journal of Management Studies, 38(4), 489-513.

Bansal, P., \& Hunter, T. (2003). Strategic explanations for the early adoption of ISO14001, J ournal of Business Ethics, 46, 289-299.

Bansal, P., \& Roth, K. (2000). Why companies go green: A model of ecological responsiveness. Academy of Management J ournal, 43(4), 717-736.

Chavan, M. (2005). An appraisal of environment management systems: A competitive advantage for small businesses. Management of Environmental Quality, 16(5), 444-463.

Christmann, P. (2000). Effects of "best practices" of environmental management on cost advantage: the role of complementary assets. Academy of Management Journal, 43(4) 663-680.

Delmas, M. (2001). Stakeholders and Competitive Advantage: the case of ISO 14001. Production and Operation Management. 10(3): 343-358.

Hart, S.L. (1995). A natural resource-based view of the firm. Academy of Management Review, 20, 986-1014.

Hart, S.L. (1997). Beyond greening: Strategies for a sustainable world. Harvard Business Review, 75(1) 66-76.

Madu, C. N. (2004). Achieving competitive advantage through quality and environmental management. Environmental Quality Management, 14(2), 59-76.

Porter, M.E. (1980). Competitive strategy. New York: Free Press.

Sarkis, J. (1998). Evaluating environmentally conscious business practices. European J ournal of Operational Research, 108, 159-174.

Sharma, S., \& Vredenburg, H. (1998). Proactive corporate environmental strategy and the development of competitively valuable organizational capabilities. Strategic Management J ournal, 1(8), 729-753. 
Shrivastava, P. (1995). Environmental technologies and competitive advantage. Strategic Management Journal, 16, 183-200.

Simpson, M., Taylor, N., \& Barker, K. (2004). Environmental responsibility in SMEs: does it deliver competitive advantage?. Business Strategy and the Environment, 13(3), 156-171.

Stead, W. E.; Stead, J. G. (1996). Management for a small planet. London: Sage.

Tien, S-W., Chung, Y-C., \& Tsai, C-H. (2005). An empirical study on the correlation between environmental design implementation and business competitive advantages in Taiwan's industries. Technovation, 25, 783-794.

Zutshi, A., \& Sohal, A. (2004). Environmental Management system adoption by Australasian Organizations: part 1: reasons, benefits and impediments. Technovation, 24, 335-357.

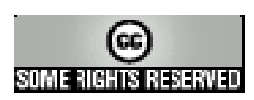

Article's contents are provided on an Attribution-Non Commercial 3.0 Creative commons license. Readers are allowed to copy, distribute and communicate article's contents, provided the author's and Journal of Industrial Engineering and Management's names are included. It must not be used for commercial purposes. To see the complete license contents, please visit http://creativecommons.org/licenses/by-nc/3.0/. 